\title{
INHIBITION OF INTRACELLULAR PROLIFERATION OF LEISHMANIA PARASITES IN VITRO AND SUPPRESSION OF SKIN LESION DEVELOPMENT IN BALB/C MICE BY A NOVEL LIPID A ANALOG (ONO-4007)
}

\author{
MOHAMMED A. K. KHAN, MOTOYOSHI MARUNO, NOOR M. KHASKHELY, SAEEF T. RAMZI, \\ ATSUSHI HOSOKAWA, HIROSHI UEZATO, EDUARDO A. GOMEZ LANDIRES, YOSHIHISA HASHIGUCHI, AND \\ SHIGEO NONAKA \\ Department of Dermatology, Faculty of Medicine, University of the Ryukyus, Nishihara-cho, Okinawa, Japan; Department of \\ Tropical Medicine, Faculty of Medicine, Catholic University of Santiago de Guayaquil, Guayaquil, Ecuador; Department of \\ Parasitology, Kochi Medical School, Nangoku, Kochi, Japan
}

\begin{abstract}
A synthetic lipid A analog (ONO-4007) exhibits antileishmanial activity by activating Leishmania-infected macrophages in experimental leishmaniasis. In the present in vitro study, ONO-4007 at concentrations between 0.01 and $1.00 \mathrm{mg} / \mathrm{mL}$ markedly inhibited the proliferation of Leishmania major and L. amazonensis promastigotes. Ultrastructurally, L. major-infected macrophages showed degenerated intracellular amastigotes after exposure to ONO-4007. Leishmania-infected macrophages treated with ONO-4007 showed poorly developed parasitophorous vacuoles. High levels of tumor necrosis factor-alpha were induced by ONO-4007 in Leishmania-infected macrophages. In this in vivo study, L. amazonensis-infected BALB/c mice were treated with a dose of $30 \mathrm{mg} / \mathrm{kg}$ of ONO-4007 by perilesional and peritoneal injections. The skin lesion size was assessed before treatment with ONO-4007 and at eight weeks after injection. The lesion size was significantly suppressed in mice perilesionally injected with ONO-4007 $(P<0.01)$ compared with the controls. The data from our present in vitro and in vivo studies indicate that ONO-4007 has an antileishmanial effect.
\end{abstract}

\section{INTRODUCTION}

Leishmaniasis is a widespread, infectious parasitic disease caused by Leishmania spp. The World Health Organization estimates that 350 million people are at risk of infection with leishmaniasis in endemic areas and that approximately 12 million are currently infected, with 400,000 new cases each year. ${ }^{1,2}$ It is now a worldwide problem and a great challenge exists in the fight against this disease. At the present time, commercially available, antimonial compounds remain the first-line drugs of choice in spite of reported severe toxicity affecting the heart, liver, and kidneys. ${ }^{3}$ However, instead of using metallic antimonial agents in the treatment of leishmaniasis, investigators have been introducing different chemotherapeutic agents with different methods of administration. ${ }^{4}$ Studies in endemic areas have reported strains of Leishmania that are resistant to antimonial compounds. ${ }^{3,5}$ Safe, effective, and sensitive chemotherapeutic agents that kill Leishmania parasites have been the subjects of intense research to discover new drugs for solving this worldwide health problem.

ONO-4007, a novel synthetic lipid A analog, has been reported to exhibit strong antitumor activity in various experimental animal models via intratumor production of the tumor necrosis factor-alpha (TNF- $\alpha)$ with lower toxicity than has been exhibited with bacterial lipopolysaccharide (LPS). ${ }^{6}$ Lipid A is an active part of LPS, a component of the cell wall of gram-negative bacteria that has a variety of biologic activities, including both beneficial immunopotentiating activity and toxicity. ${ }^{7,8}$ The chemical structure of ONO-4007 (sodium2-deoxy-2[3S-(9-phenylnonanoyloxy)tetradecanoyl]-amino3-0-(9-phenylnonanoyl)-D-glucopyranose 4-sulfate) is shown in Figure 1. This analog activates macrophages, which then release large amounts of TNF- $\alpha$ in a dose-dependant manner. ${ }^{9,10}$ Moreover, in vitro studies have shown that pretreatment of human monocytes with granulocyte-macrophage colony-stimulating factor enhances the production of TNF- $\alpha$ in response to ONO-4007. ${ }^{11}$ It has been reported that ONO4007 contributes to the induction of nitric oxide (NO) syn- thase in macrophage cell lines J774.2, resulting in the formation of cytotoxic NO, which may show antitumor activity in vitro. ${ }^{12}$

Macrophages are activated when exposed to cytokines to eliminate intracellular infections by microorganisms. ${ }^{13}$ In infections with Leishmania, cytokines such as interferongamma (IFN- $\gamma$ ), migration inhibitory factor, and TNF- $\alpha$ are capable of inducing leishmaniacidal activity in vitro. ${ }^{15-20}$ The leishmaniacidal activity of macrophages is also mediated by $\mathrm{NO}^{21}$ after activation by cytokines and LPS. ${ }^{21,22}$ These data indicate that ONO-4007 may contribute to the elimination of Leishmania parasites from infected subjects.

In this study, we examined the antileishmanial efficacy of ONO-4007 in experimental leishmaniasis in vitro and in vivo, with the aim of introducing a new drug strategy for treatment of leishmaniasis. The inhibitory effects of ONO-4007 on Leishmania proliferation were investigated in promastigotes and amastigotes, and in L. amazonensis-infected BALB/c mice.

\section{MATERIALS AND METHODS}

In vitro study. Parasites. Two strains of Leishmania promastigotes, L. major (MHOM/SU/73/5ASKH) and L. amazonensis (MHOM/BR/73/M2269), were cultured in RPMI 1640 medium (GIBCO-BRL, Tokyo, Japan) medium supplemented with $10 \%$ fetal bovine serum (FBS), 50 units/mL of penicillin, and $50 \mu \mathrm{g} / \mathrm{mL}$ of streptomycin.

Macrophage culture. Macrophage cell line J774 was obtained from the Dai Nippon Pharmaceutical Co. (Osaka, Japan), and was cultured in Dulbecco's minimal essential medium (GIBCO-BRL) supplemented with 10\% FBS, 50 units/ $\mathrm{mL}$ of penicillin, and $50 \mu \mathrm{g} / \mathrm{mL}$ of streptomycin. Laboratory$\mathrm{Tek}^{\circledR}$ tissue culture chamber slides (Nalge Nunc International Corp., Naperville, IL) were used for cell culture and kept in an incubator at $37^{\circ} \mathrm{C}$ in an atmosphere of $5 \% \mathrm{CO}_{2}$ and a humidity of $95 \%$.

Drug. ONO-4007 was generously provided by the Ono 




FIgURE 1. Chemical structure of ONO-4007.

Pharmaceutical Co. (Osaka, Japan). The drug was prepared in $5 \%$ ethanol in a $4.5 \%$ glucose solution.

Drug administration. Promastigotes of $L$. major and $L$. amazonensis were exposed to ONO-4007 at concentrations of $0 \mathrm{mg} / \mathrm{mL}, 0.01 \mathrm{mg} / \mathrm{mL}, 0.10 \mathrm{mg} / \mathrm{mL}$ and $1.00 \mathrm{mg} / \mathrm{mL}$ for 48 hours. Similarly, macrophages infected with $L$. major were incubated with ONO-4007 at the same dosages for 48 hours.

Parasite count. Promastigotes in the medium were counted with a hemocytometer.

Enzyme-linked immunosorbent assay (ELISA) for TNF- $\alpha$.. The expression of TNF- $\alpha$ in culture supernatants was determined by a sandwich ELISA using a commercially available TNF- $\alpha$ kit (Endogen, Woburn, MA) according to the protocol provided by the manufacturer. The level of TNF- $\alpha$ was expressed as micrograms per milliliter $/ 2.08 \times 10^{6}$ macrophage cells. All measurements were carried out in triplicate.

Electron microscopy. Macrophages were harvested and washed twice with phosphate-buffered saline. They were fixed with $2 \%$ glutaraldehyde in $0.1 \mathrm{M}$ cacodylate buffer, and then treated with phosphate-buffered $1 \%$ osmium tetroxide for one hour. The samples were dehydrated with a graded ethanol series and propylene oxide. The samples were then embedded in Epon 812 resin and ultrathin sections were cut. The sections were stained with uranyl acetate, counterstained with lead citrate, and then observed with a JEOL 2000EX electron microscope (JEOL, Tokyo, Japan).

In vivo study. Infection of mice with parasites. Female $\mathrm{BALB} / \mathrm{c}$ mice (6-8 weeks old) were used in these experi- ments. They were strictly maintained under the rules and regulations of the Animal Welfare Center (University of the Ryukyus, Okinawa, Japan) in specific pathogen-free conditions with laminal air flow. All mice were inoculated intradermally on the shaved skin of their backs with $2 \times 10^{7} \mathrm{~L}$. amazonensis promastigotes.

Drug administration. After the skin lesion was confirmed (five weeks after inoculation), a $30 \mathrm{mg} / \mathrm{kg}$ dose of ONO-4007 was perilesionally or peritoneally injected into the mice twice a week for eight consecutive weeks. Mice were divided into four groups: group A (vehicle only, perilesional injection, $\mathrm{n}=$ 7), group B (vehicle only, peritoneal injection, $\mathrm{n}=8$ ), group $\mathrm{C}(\mathrm{ONO}-4007$, perilesional injection, $\mathrm{n}=6)$, and group $\mathrm{D}$ (ONO-4007 peritoneal injection, $\mathrm{n}=6$ ).

Assessment of the lesion size. Lesion size was measured with a dial caliper before and after eight weeks of treatment with ONO-4007 and expressed as the area of lesion (long axis $\times$ short axis in $\mathrm{mm}^{2}$ ).

Statistical analysis. Statistical differences were examined by the unpaired $t$-test. The level of significance was determined at $P<0.05$.
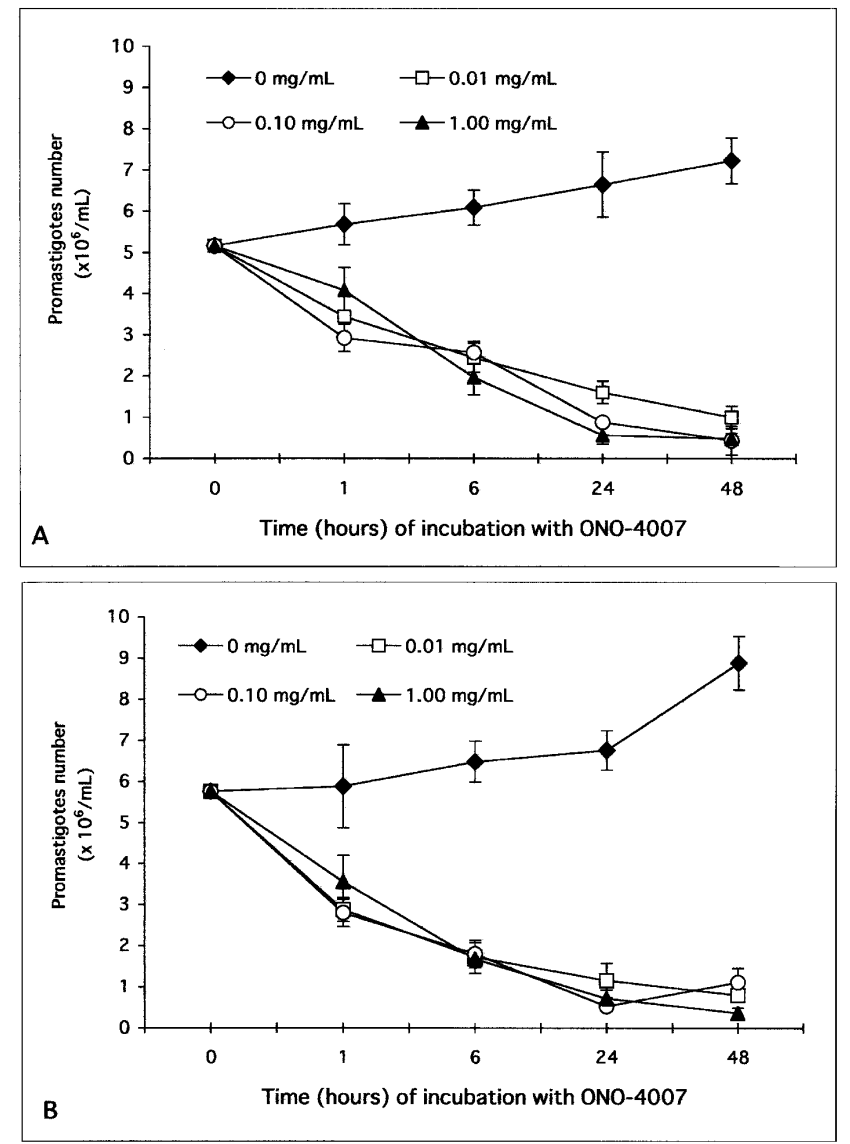

FIGURE 2. Inhibition of growth of Leishmania promastigotes in culture medium incubated with ONO-4007. Promastiogotes of L. major (A) and L. amazonensis (B) showed a gradual reduction in numbers when exposed to $0.01-1.00 \mathrm{mg} / \mathrm{mL}$ of ONO-4007 for 48 hours. Both strains of promastigotes proliferated in the absence of ONO4007. A significant reduction in number of promastigotes was observed following incubation with the drug for $24-48$ hours. The proliferation of L. major and L. amazonensis was inhibited by ONO4007. Bars show the mean \pm SD of four experiments. 


\section{RESULTS}

Anti-promastigote activity of ONO-4007. Promastigotes of L. major and L. amazonensis were cultured with 0, 0.01, 0.10, and $1.00 \mathrm{mg} / \mathrm{mL}$ of ONO-4007 for 48 hours. In the absence of ONO-4007, both strains of Leishmania promastigotes proliferated over time. In contrast, both types of promastigotes treated with ONO-4007 gradually decreased in number in a time-dependent fashion. After 24 and 48 hours of incubation with three different drug concentrations, L. major promastigotes showed a significant reduction in number when compared with the controls. No significant differences in the number of L. major promastigotes were observed for the three different concentrations of drug after 48 hours of incubation (Figure 2A). However, the number of L. amazonensis promastigotes was significantly reduced at the three different drug concentrations when compared with the controls following incubation for 24 and 48 hours (Figure 2B). Statistically significant differences were observed at a concentration of $1.00 \mathrm{mg} / \mathrm{mL}$ compared with $0.01 \mathrm{mg} / \mathrm{mL}(P<0.01)$ and at a concentration of $1.00 \mathrm{mg} / \mathrm{mL}$ compared with $0.10 \mathrm{mg} / \mathrm{mL}$ following 48 hours of incubation $(P<0.01)$. These results demonstrate the inhibition of the growth of L. major and L. amazonensis promastigotes by ONO-4007.

Promastigotes cocultured with macrophages. This study was performed to estimate the time required for Leishmania promastigotes to enter murine macrophages. Cocultivation showed that approximately $80 \%$ of the promastigotes of $L$. major and L. amazonensis in the medium entered macrophages after 24 hours (Figure 3). Thus, ONO-4007 should be given after 24 hours of cocultivation with the macrophages.

Expression of TNF- $\alpha$ by $L$. major-infected macrophages. Production of TNF- $\alpha$ by macrophages infected with L. major following incubation for 24 hours with three concentrations

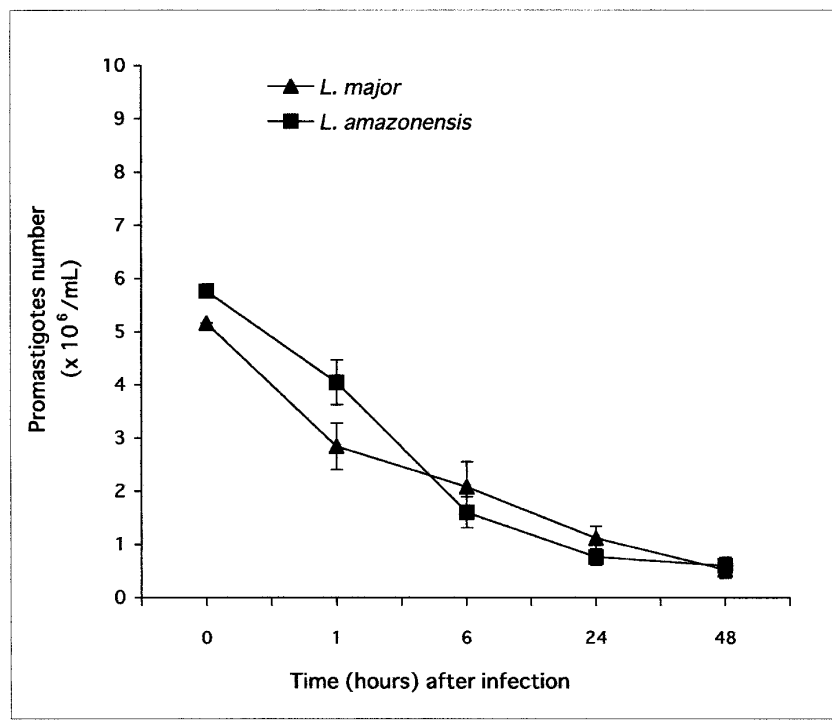

Figure 3. Numbers of Leishmania major and L. amazonensis promastigotes in culture medium cocultured with J774 macrophages. Both strains of Leishmania promastigotes show a gradual reduction in number. After 24 hours of cocultivation, a reduction of approximately $80 \%$ in number of promastigotes in both strains is observed, which indicates that approximately $80 \%$ of the initial inoculated promastigotes have entered the macrophages. Bars show the mean \pm SD of four experiments.
(0.01 mg/mL, $0.10 \mathrm{mg} / \mathrm{mL}$, and $1.00 \mathrm{mg} / \mathrm{mL}$ ) was examined by sandwich ELISA. The culture supernatant was collected and analyzed after incubation for 6,12 , and 24 hours with ONO4007. Production of TNF- $\alpha$ was significantly induced by ONO-4007 at all three concentrations. The highest level of $\mathrm{TNF}-\alpha$ was observed after incubation for six hours with all concentrations of drug, and gradually decreased in a timedependent manner (Figure 4). After incubation for six hours, the level of TNF- $\alpha$ was significantly higher at drug concentrations of $0.01 \mathrm{mg} / \mathrm{mL}, 0.10 \mathrm{mg} / \mathrm{mL}$, and $1.00 \mathrm{mg} / \mathrm{mL}$ when compared with the controls $(P<0.01, P<0.001$, and $P<0.01$, respectively). Induction of TNF- $\alpha$ after incubation for six hours at ONO-4007 concentrations of $0.01 \mathrm{mg} / \mathrm{mL}$ and 0.10 $\mathrm{mg} / \mathrm{mL}$ was higher than at the concentration of $1.00 \mathrm{mg} / \mathrm{mL}$.

Electron microscopy of $L$. major-infected macrophages. Macrophages in the absence of ONO-4007 showed many intracellular amastigotes within markedly large parasitophorous vacuoles (Figure 5A). At a higher magnification, oval amastigotes showed well-developed cell organelles (Figure 5C). Conversely, macrophages treated with ONO-4007 showed only a few amastigotes and poorly formed parasitophorous vacuoles in the macrophages (Figure 5B). At a higher magnification, intracellular amastigotes showed degenerative changes and poorly formed parasitophorous vacuoles (Figure 5D).

Lesion development in $L$. amazonensis-infected mice. BALB/c mice infected on their backs with L. amazonensis promastigotes showed skin lesions as a single nodule with or without ulceration five weeks after inoculation. The lesions developed to full size in most of the infected mice. However,

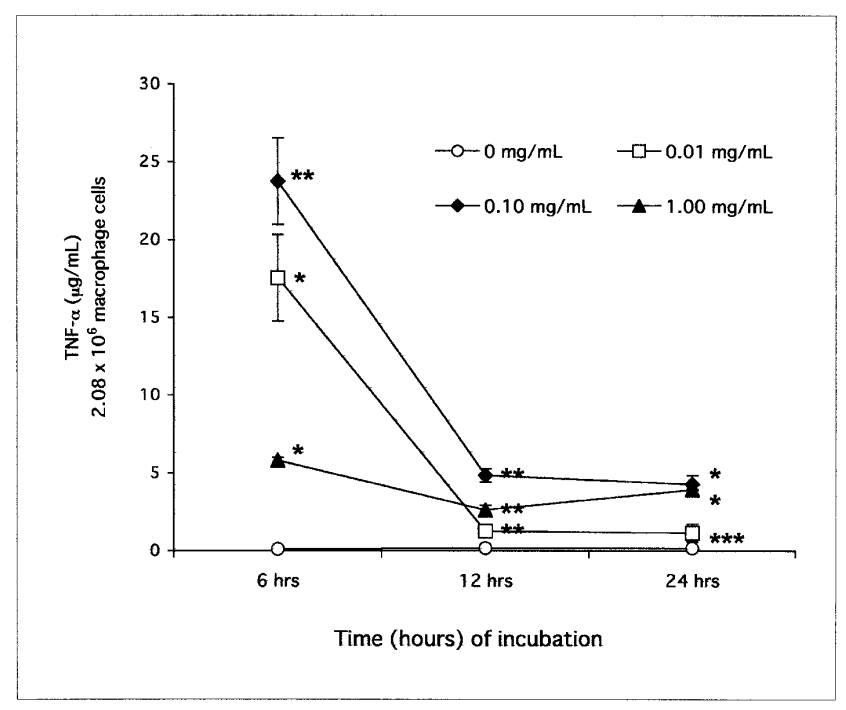

FIGURE 4. Production of tumor necrosis factor-alpha (TNF- $\alpha$ ) by Leishmania major-infected macrophages in response to three different concentrations of ONO-4007 $(0.01 \mathrm{mg} / \mathrm{mL}, 0.10 \mathrm{mg} / \mathrm{mL}$, and 1.00 $\mathrm{mg} / \mathrm{mL}$ ). The cells were cocultured with L. major for 24 hours and then incubated with three concentrations of ONO-4007 for 6, 12, and 24 hours. Production of TNF- $\alpha$ by L. major-infected macrophages was calculated per $2.08 \times 10^{6}$ macrophages. The high level of TNF- $\alpha$ production was observed after incubation for six hours at three different concentrations. All measurements were carried out in triplicate. Bars show the mean \pm SD. Statistical analysis was performed to compare the controls with three different concentrations of ONO4007 after incubation for 6,12 , and 24 hours. $* P<0.001$; $* * P<$ $0.01 ; * * P<0.05$. 

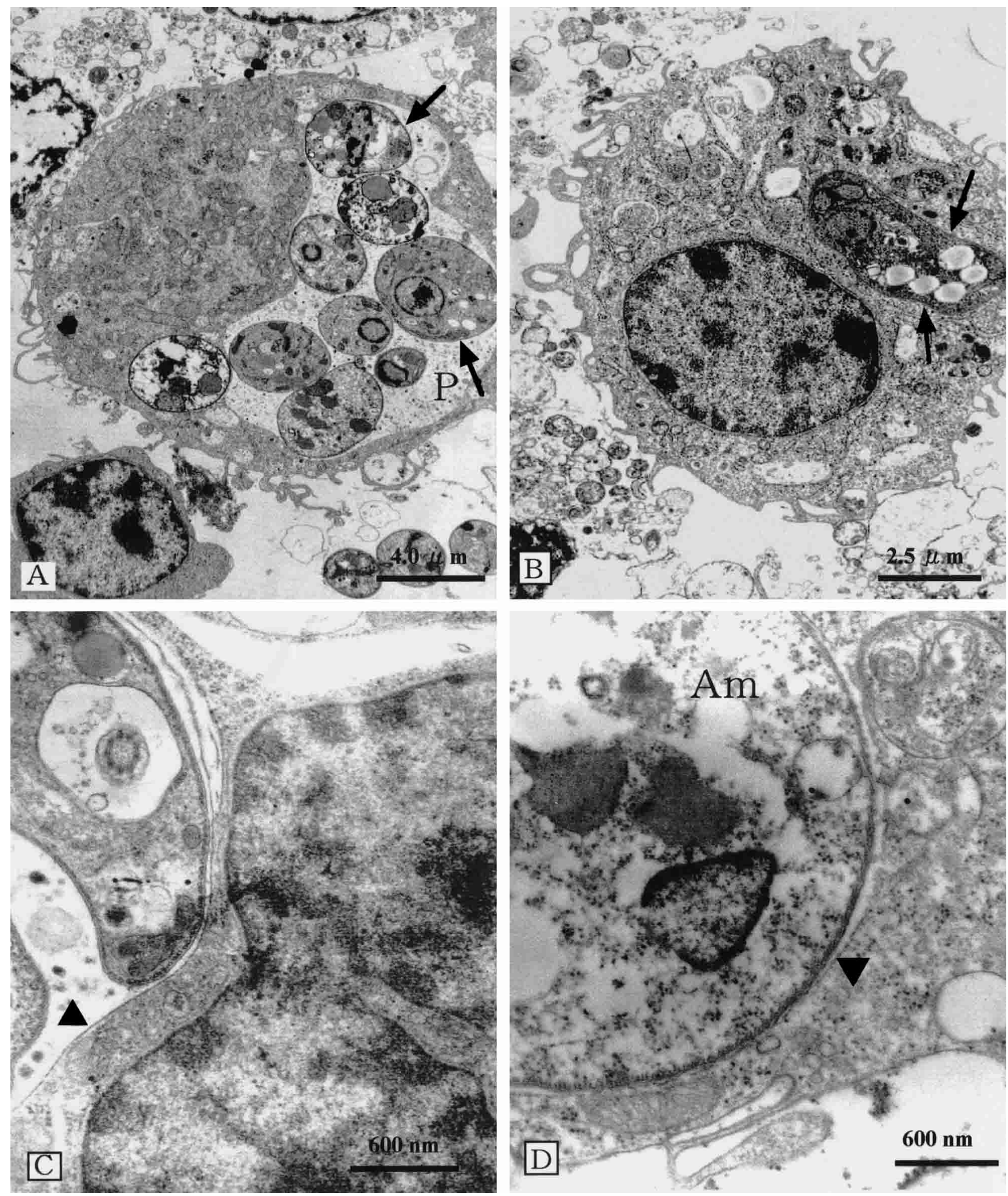

FIGURE 5. Ultrastructure of Leishmania major-infected macrophages. A, L. major-infected macrophages used as a control shows large parasitophorous vacuoles (P) containing many Leishmania parasites (arrows). B, an L. major-infected macrophage treated with ONO-4007 contains a single Leishmania parasite (arrows), but parasitophorous vacuoles are too small to identify. C, Higher magnification view of control macrophages, showing formation of a parasitophorous vacuole with a well-developed membrane (arrowhead). D, Higher magnification of macrophages treated with ONO-4007, showing poor formation of parasitophorous vacuoles compared with the control (arrowhead) and an amastigote (Am) inside the parasitophorous vacuole with degenerative changes. 
four mice in group $\mathrm{C}$ (ONO-4007 perilesionally injected mice) showed healed lesions eight weeks after treatment (Figure 6C). The mean (SD) size of the skin lesions in each group is shown in Figure 7. Lesion development was significantly suppressed in mice perilesionally injected with ONO-4007 $(P<$ $0.01)$ compared with mice injected with the vehicle (group A). No statistically significant difference in lesions was observed between mice peritoneally injected with ONO-4007 (group D) and mice injected with the vehicle (group B).

\section{DISCUSSION}

This study provides evidence that ONO-4007 inhibits promastigote proliferation. However, in the elimination of Leishmania parasites in vivo, activation of macrophages may be the most critical factor because the disease course is influenced by several cytokines. ${ }^{23-26}$ Activation of macrophages can estimated by endogenous production of TNF- $\alpha$ and confirmed by ultrastructural findings, such as well-developed mitochondria, endoplasmic reticulum, and other cell organelles. In previous reports, ONO-4007 induced higher levels of endogenous production of TNF- $\alpha$ and cytocidal activities against MM46 mammary/KDH-8 hepatoma cells than LPS in vitro and in vivo. ${ }^{6,11}$

In the present study, ONO-4007 induced production of TNF- $\alpha$ in Leishmania-infected macrophages at concentrations of $0.01-1.00 \mathrm{mg} / \mathrm{mL}$, especially at $0.10 \mathrm{mg} / \mathrm{mL}$. Tumor necrosis factor-alpha is also a pleotrophic cytokine that may stimulate a variety of potent antimicrobial mechanisms ${ }^{27,28}$ and have a protective role against infection with $L$. major. ${ }^{18,19}$ Our ultrastructural observations of Leishmania-infected macrophages treated with ONO-4007 revealed degenerative change in amastigotes, dilated rough endoplasmic reticulum, and large mitochondria. These results supported our theory that ONO-4007 promotes antileishmanial activity by activation of Leishmania-infected macrophages. Ultrastructural study showed that in the ONO-4007-treated macrophages, the number of amastigotes was much less than in the controls.

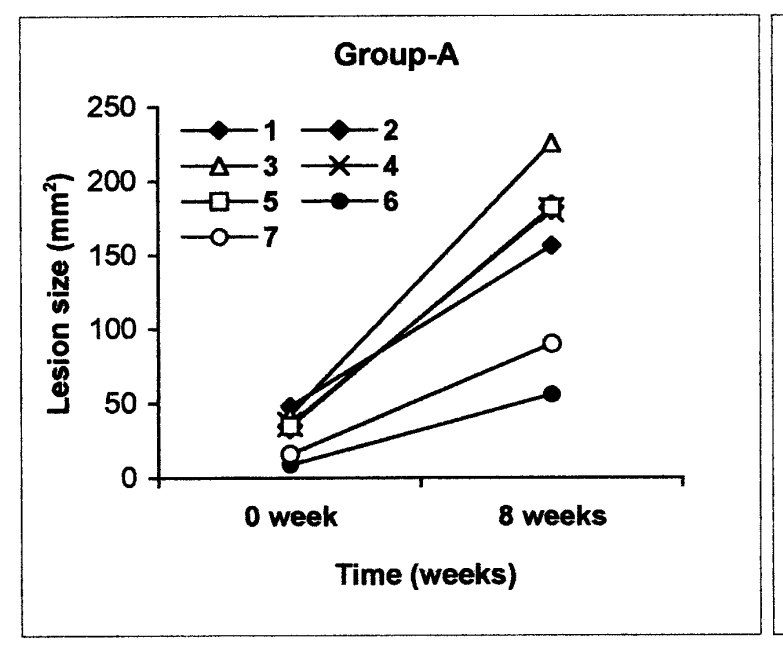

A

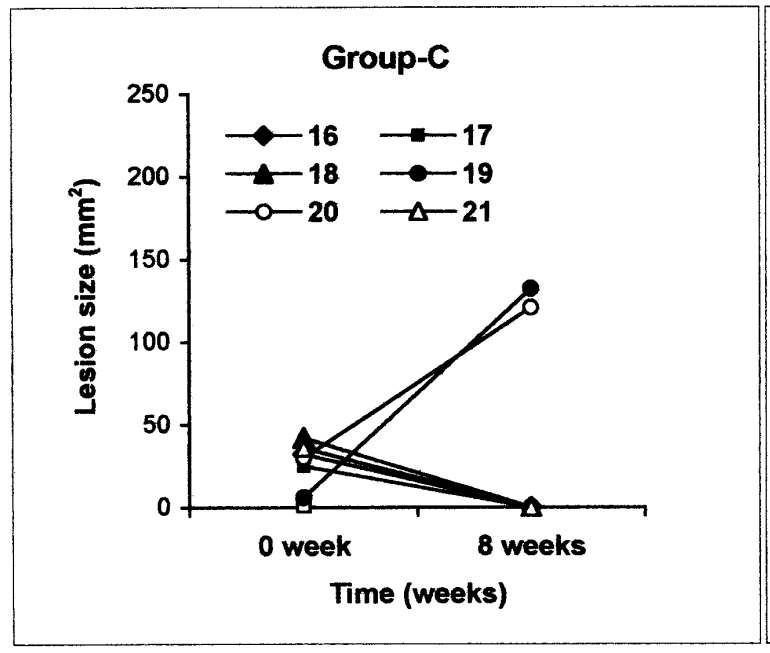

C

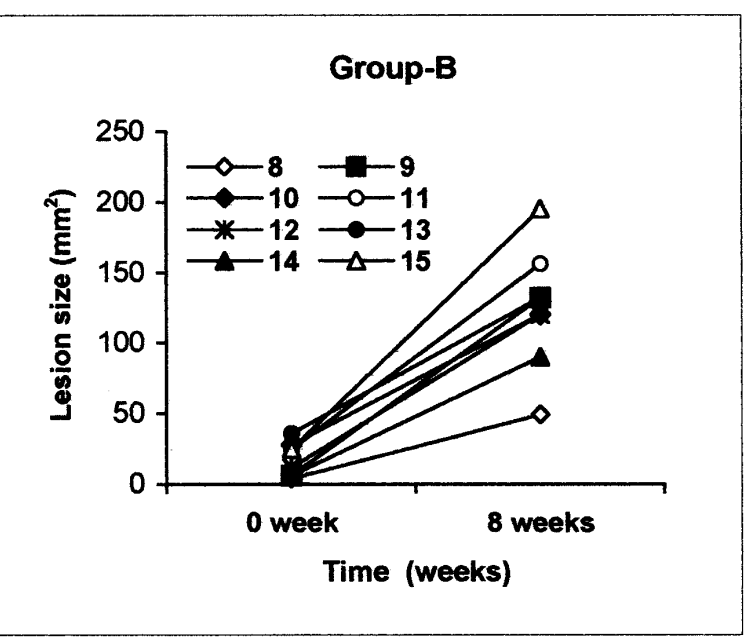

B

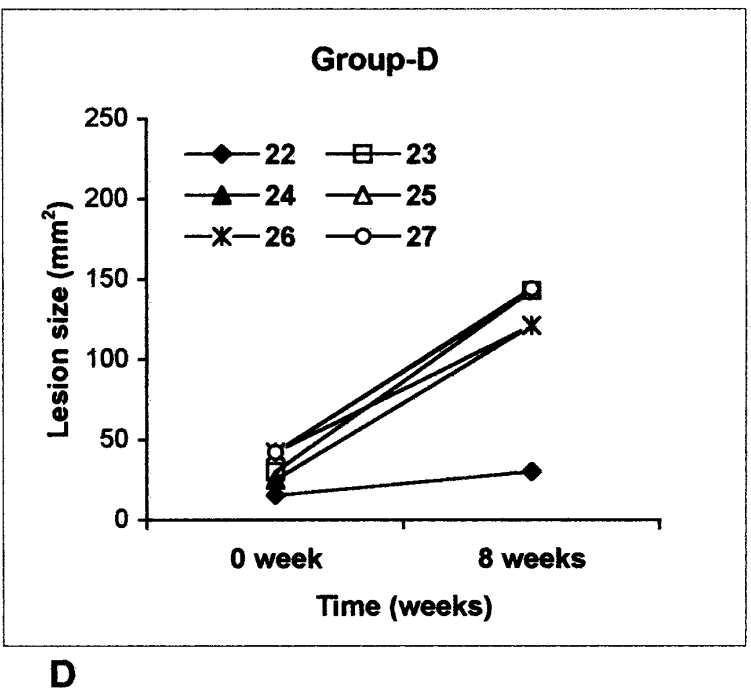

FIGURE 6. Area (long axis $\times$ short axis in $\mathrm{mm}^{2}$ ) of skin lesions of Leishmania amazonensis-infected BALB/c mice before and after eight weeks treatment with ONO-4007. A, Mice in group A $(n=7)$ were perilesionally injected with vehicle. B, Mice in group B $(n=8)$ were peritoneally injected with vehicle. $\mathbf{C}$, Mice in group $\mathrm{C}(\mathrm{n}=6)$ were perilesionally injected with ONO-4007 (note that the lesions healed in four mice). $\mathbf{D}$, Mice in group $\mathrm{D}(\mathrm{n}=6)$ were peritoneally injected with ONO-4007. 


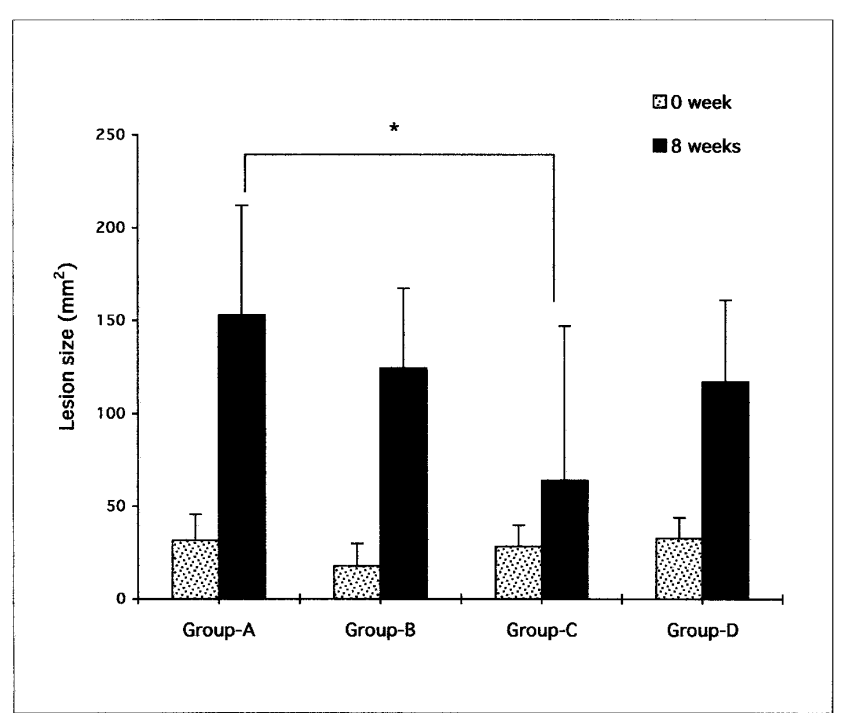

FIGURE 7. Lesion sizes of Leishmania amazonensis-infected mice. Mice perilesionally injected with ONO-4007 mice (Group C) show significant suppression of lesion development compared with the controls. No significant difference was observed between mice peritoneally injected with either vehicle or ONO-4007. Groups A, B, $\mathrm{C}$, and D consisted of seven, eight, six, and six mice, respectively. Bars show the mean and $\mathrm{SD} .{ }^{*} P<0.01$, group $\mathrm{C}$ versus group $\mathrm{A}$.

The most striking feature of the study was the formation of parasitophorous vacuoles in the infected macrophages. The parasitophorous vacuoles were very large in cells not treated with ONO-4007, and they contained several amastigotes. In contrast, cells treated with ONO-4007 cells did not show extensive formation of these vacuoles. Parasitophorous vacuoles are a sign of intracellular parasite survival. ${ }^{29}$ Poor formation of these vacuoles in cells treated with ONO-4007 cells suggests that amastigote activity was inhibited by the treatment.

In our in vitro study, we used ONO-4007 in a murine model of leishmanisis. After checking the development of lesions, we injected this drug perilesionally and peritoneally. In mice injected perilesionally with ONO-4007 (group C), lesion development was significantly suppressed compared with the controls (group A). It is noteworthy that four mice in group C showed healed lesions, although lesion development in these mice was variable. In the peritoneally injected group, there was no significant difference between the drug and control groups. These results suggests that ONO-4007 might have an antileishmanial effect in the in vivo model, as well as in the in vitro model. The toxic effect of ONO-4007 was very negligible, a 1,000-fold less than that of Escherichia coli LPS. This has been shown in previous reports. ${ }^{6,10,11}$ In human monocytes/macrophages, ONO-4007 stimulates higher levels of TNF- $\alpha$ production with lower toxicity than bacterial LPS. ${ }^{11}$ Lipopolysaccharide has never been used in humans due to its strong toxicity. Based on these observations, ONO-4007 may be a practical therapeutic agent for treatment of leishmaniasis. We used only one dose $(30 \mathrm{mg} / \mathrm{kg})$ of the drug in the in vivo study. Several dosage levels should be tested in mice in future studies.

Killing of intracellular parasites by macrophages has been shown to be mediated by NO both in vitro ${ }^{30,31}$ and in vivo. ${ }^{31}$ Recent studies have shown that NO is a potent antimicrobial agent $^{21}$ derived from L-arginine by the enzyme NO synthase. ${ }^{32,33}$ The cytokines TNF- $\alpha$ and IFN- $\gamma$ are the important immunologic mediators in the induction of NO synthase in macrophages. ${ }^{34,35}$ The conversion of L-arginine to NO is catalyzed by the enzyme NO synthase, which is induced in macrophages after activation of cytokines by LPS. ${ }^{21,22}$ The Th1 cytokine response and the production of IFN- $\gamma^{25,26}$ are required for the induction of inducible NO synthase in infected macrophages. ${ }^{30,31,36}$ ONO-4007 induced NO synthase resulting in the formation of cytotoxic NO, which may contribute to the antitumor activity that has been shown in both in vivo and in vitro studies. ${ }^{12}$ It has been reported that intracellular killing of Leishmania parasites within macrophages was enhanced in the presence of TNF- $\alpha$ together with IFN- $\gamma$ or LPS. ${ }^{14,19} \mathrm{Nei}-$ ther IFN- $\gamma$ nor LPS alone induced leishmaniacidal activities in vitro, indicating that LPS was necessary as a secondary stimulus. ${ }^{17}$ Although our experiment was not specifically designed to determine the exact mechanism(s) by which ONO4007 exerted an antileishmanial agent, it is suggested that the role of NO and Th1 cytokine induction should be the subject of intense research in further in vivo studies using experimental leishmanial mice.

Acknowledgments: We are grateful to the Ono Pharmaceutical Co. for providing ONO-4007 and financial support. We thank M. Randall for checking the final manuscript. We also thank Yoko Zukeran, Keiko Kohama, Ritsuko Nakamura, and Ayako Nakamura for technical support during this study.

Financial support: This work was supported in part by Grants-in-Aid for Science Research to Motoyoshi Maruno (11770471 and 13770458) and Yoshihisa Hashiguchi (07557209) from the Ministry of Education, Science, Sports and Culture of Japan.

Authors' addresses: Mohammed A. K. Khan, Motoyoshi Maruno, Noor M. Khaskhely, Saeef T. Ramzi, Atsushi Hosokawa, Hiroshi Uezato, and Shigeo Nonaka, Department of Dermatology, Faculty of Medicine, University of the Ryukyus, Nishihara-cho, Okinawa 9030215, Japan. Eduardo A. Gomez Landires, Department of Tropical Medicine, Faculty of Medicine, Catholic University of Santiago de Guayaquil, PO Box. 10833, Guayaquil, Ecuador. Yoshihisa Hashiguchi, Department of Parasitology, Kochi Medical School, Nangoku, Kochi, 783-8505, Japan.

Reprint requests: Mohammed A. K. Khan, Department of Dermatology, Faculty of Medicine, University of the Ryukyus, Nishiharacho, Aza Uehara 207, Okinawa 903-0215, Japan, Fax: 81-98-895-1417. E-mail: k998761@med.u-ryukyu.ac.jp

\section{REFERENCES}

1. Report of a WHO expert committee, 1990. Control of the leishmaniases. World Health Organ Tech Rep Ser 793: 1-158.

2. Ashford RW, Desjeux P, DeRaadt P, 1992. Estimation of population at risk of infection and number of cases of leishmaniasis. Parasitol Today 8: 104-105.

3. Ollario PL, Bryceson ADM, 1993. Practical progress and new drugs for changing patterns of leishmaniasis. Parasitol Today 9: 323-328.

4. Koff AB, Rosen T, 1994. Treatment of cutaneous leishmaniasis. J Am Acad Dermatol 31: 693-708.

5. Lainson R, Shaw JJ, 1987. Evolution, Classification and Geographical Distribution of Leishmania. Peters W, KillickKendrick R, eds. The Leishmaniases in Biology and Medicine. Volume 1. London: Academic Press, 1-120.

6. Matsumoto N, Oida H, Aze Y, Akimoto A, Fujita T, 1998. Intratumoral tumor necrosis factor induction and tumor growth suppression by ONO-4007, a low toxicity lipid A analog. Anticancer Res 18: 4283-4289.

7. Morrison DC, Ryan JL, 1979. Bacterial endotoxins and host immune responses. Adv Immunol 28: 293-450. 
8. Somlyo B, Csanky E, Shi XM, Zhang YL, Kovats E, Bona-Liptak E, Nowotony AM, di Tripo D, 1992. Molecular requirement of endotoxin (ET) actions: changes in the immune adjuvant, TNF liberating and toxic properties of endotoxin during alkaline hydrolysis. Int J Immunopharmacol 14: 131-142.

9. Kuramitsu Y, Nishibe M, Ohiro Y, Matsushita K, Yuan L, Obara M, Kobayashi M, Hosokawa M, 1997. A new synthetic lipid a analog, ONO-4007, stimulates the production of tumor necrosis factor-alpha in tumor tissues, resulting in the rejection of transplanted rat hepatoma cells. Anticancer Drugs 8: 500-508.

10. Yang D, Satoh M, Ueda H, Tsukagoshi S, Yamazaki M, 1994. Activation of tumor infiltrating macrophages by a synthetic lipid A analog (ONO-4007) and its implication in antitumor effects. Cancer Immunol Immunother 38: 287-293.

11. Mastumoto N, Aze Y, Akimoto A, Fujita T, 1998. ONO-4007, an antitumor lipid A analog, induces tumor necrosis factor- $\alpha$ production by human monocytes only under primed state: different effects of ONO-4007 and lipoploysaccharide on cytokine production. J Pharmacol Exp Ther 284: 189-195.

12. Hattori Y, Szabo C, Gross S, Thiemermann C, Vane JR, 1995. Lipid A and the lipid A analogue anti-tumour compound ONO-4007 induce nitric oxide synthase in vitro and in vivo. Eur J Pharmacol 291: 83-90.

13. Hibbs JB Jr, Vavrin Z, Taintor RR, 1987. L-arginine is required for expression of the activated macrophage effector mechanism carrying selective metabolic inhibition in target cells. $J$ Immunol 138: 550-565.

14. Bogdan C, Moll H, Solbach W, Röllinghoff M, 1990. Tumor necrosis factor-alpha in combination with interferon-gamma but not with interleukin-4 activates murine macrophages for elimination of Leishmania major amastigotes. Eur J Immunol 20: $1131-1135$.

15. Liew FY, Li Y, Millott S, 1990. Tumor necrosis factor- $\alpha$ synergies with IFN- $\alpha$ in mediating killing of Leishmania major through the induction of nitric oxide. J Immunol 145: 4306-4310.

16. Green SJ, Crawford RM, Hockmeyer JT, Meltzer MS, Nacy CA, 1990. Leishmania major amastigotes initiate the L-argininedependent killing mechanism in IFN- $\gamma$ stimulated macrophages by induction of tissue necrosis factor-alpha. J Immunol 145: 4290-4297.

17. Roach TIA, Kiderlen AF, Blackwell JM, 1991. Role of inorganic nitric oxides and tumor necrosis factor-alpha in killing Leishmania donovani amastigotes in gamma interferon-lipopolysaccharide-activated macrophages from $\mathrm{Lsh}^{\mathrm{s}}$ and $\mathrm{Lsh}^{\mathrm{r}}$ congenic mouse starins. Infect Immun 59: 3935-3944.

18. Titus RG, Sherry B, Cerami A, 1989. Tumor necrosis factor plays a protective role experimental murine cutaneous leishmaniasis. J Exp Med 170: 2097-2104.

19. Liew FY, Parkinson C, Millot S, Severn A, Carrier M, 1990. Tumor necrosis factor (TNF- $\alpha$ ) in leishmaniasis. I. TNF- $\alpha$ mediates host protection against cutaneous leishmaniasis. Iтmиnology 69: 570-573.

20. Cunha FQ, Weiser WY, David JR, Moss DW, Moncada S, Liew FY, 1993. Recombinant migration inhibitory factor induces nitric oxide synthase in murine macrophages. J Immunol 150: 1908-1912.

21. Hibbs JB Jr, Taintor RR, Vavrin Z, Granger DL, Drapier JC, Amber IJ, Lancaster JR Jr, 1990. Synthesis of nitric oxide from a terminal guanidino atom of L-arginine: a molecular mechanism regulating cellular proliferation that targets intra- cellular iron. Moncada S, Higgs EA, eds. Nitric Oxide From L-arginine: A Bio-Regulatory System. Amsterdam: Elsevier Publishers: 189-223.

22. Moncada S, Palmer RM, Higgs EA, 1989. Biosynthesis of nitric oxide from $\mathrm{L}$-arginine. A pathway for the regulation of cell function and communication. Biochem Pharmacol 38: 17091715.

23. Reed SG, Scott P, 1993. T-cell and cytokine responses in leishmaniasis. Curr Opin Immunol 5: 524-531.

24. Locksley RM, Scott P, 1991. Helper T-cell subsets in murine leishmaniasis: induction, expansion, and effector function. Immunol Today 12: A58-61.

25. Scott P, Natovitz P, Coffman RL, Pearce E, Sher A, 1988. Immunoregulation of cutaneous leishmaniasis: $\mathrm{T}$ cell lines that transfer protective immunity or exacerbation belong to different $\mathrm{T}$ helper subsets and respond to distinct parasite antigens. J Exp Med 168: 1675-1684.

26. Heinzel FP, Sadick MD, Mutha SS, Locksley RM, 1991. Production of interferon- $\gamma$, interleukin-2, interleukin- 4 , and interleukin-10 by $\mathrm{CD}^{+}$lymphocytes in vivo during healing and progressive murine leishmaniasis. Proc Natl Acad Sci USA 88: 7011-7015.

27. Talmadge JE, Tribble HR, Pennington RW, Phillips H, Wiltrout $\mathrm{RH}, 1987$. Immunomodulatory and immunotherapeutic properties of recombinant $\gamma$-interferon and recombinant tumor necrosis factor in mice. Cancer Res 47: 2563-2570.

28. Murray HW, 1990. Gamma interferon, cytokine-induced macrophage activation, and antimicrobial host defense: in vitro, in animals and humans. Diagn Microbiol Infect Dis 13: 411-421.

29. Veress B, Abdalla RE, El Hassan AM, 1981. Electron microscopic investigations on leishmaniasis in the Sudan: II. Ultrastructural morphology of macrophage-parasite interaction in human and hamster macrophages in vivo. Ann Trop Med Parasitol 75: 607-613.

30. Green SJ, Meltzer MS, Hibbs JB Jr, Nacy CA, 1990. Activated macrophages destroy intracellular Leishmania major amastigotes by an L-arginine-dependent killing mechanism. J Immunol 144: 278-283.

31. Liew FY, Millot S, Parkinson C, Palmer RMJ, Moncada S, 1990. Macrophage killing of Leishmania parasite in vivo is mediated by nitric oxide from L-arginine. J Immunol 144: 4794-4797.

32. Iyengar R, Stuehr DJ, Marletta MA, 1987. Macrophage synthesis of nitrite, nitrate and $\mathrm{N}$ - nitrosamines: precursors and role of the respiratory burst. Proc Natl Acad Sci USA 84: 6369-6373.

33. Palmer RMJ, Ashton DS, Moncada S, 1988. Vascular endothelial cells synthesize nitric oxide from L-arginine. Nature 333: 664666.

34. Ding AH, Nathan CF, Stuehr DJ, 1988. Release of reactive nitrogen intermediates and reactive oxygen intermediates from mouse peritoneal macrophages. Comparison of activating cytokines and evidence for independent production. $J$ Immunol 141: 2407-2412.

35. Drapier JC, Wietzerbin J, Hibbs JB Jr, 1988. Interferon-gamma and tumor necrosis factor induce the L-arginine dependent cytotoxic effector mechanism in murine macrophages. Eur $J$ Immunol 18: 1587-1592.

36. Mauel J, Ransijn A, Buchmuller-Rouiller Y, 1991. Killing of Leishmania parasites in activated murine macrophages is based on an L-arginine-dependent process that produces nitrogen derivatives. J Leukoc Biol 49: 73-82. 